\title{
Cue selection in discrimination learning by preschool children: Reward context effects
}

\author{
MARY ANN METZGER \\ University of Maryland Baltimore County, Catonsville, Maryland
}

\begin{abstract}
When constant or variable irrelevant cues of a two-choice visual discrimination learning problem are otherwise associated with the reward context, preschool children solve the problems more slowly than when such an association has not been established. This effect is, in the case of constant irrelevant cues, inconsistent with several attentional theories of selective learning.
\end{abstract}

The phenomena of cue selection in learning are those empirical effects in which the effectiveness of a given learning trial in changing subsequent behavior, in the presence of a particular cue, is determined by the context in which the cue is presented on the learning trial. The strength and variety of cue-selection effects in visual discrimination learning have been the focus of several theories incorporating an explicit attentional response that changes with reinforcement (Fisher \& Zeaman, 1973; Lovejoy, 1968; Sutherland \& Mackintosh, 1971; Zeaman \& House, 1963). Other theories have been proposed which attribute selection of particular cues in classical conditioning and in discrimination learning to variations in the reinforcer effectiveness or in the learning rate due to the predictive validity of other cues in the context (Mackintosh, 1975; Rescorla \& Wagner, 1972; Wagner, 1969). The theories cited apply equally well to animal and human learning (see Fisher \& Zeaman, 1973), a situation which is consonant with the observations on encoding limitations in comparative psychology noted by Premack (1983; see also Miller, 1983).

The attentional theories of Fisher and Zeaman (1973), Lovejoy (1968), and Sutherland and Mackintosh (1971) include a common, similar construct: Cue-significance differences modify the probability of attending to a given dimension. When two cues of a given dimension are equally significant predictors of reward, the effective attention to that dimension is low. When there is a large cue-significance difference, attention to that dimension is relatively high. Fundamental assumptions of these attentional theories are that attention to constant irrelevant dimensions is effectively zero and that variations in the predictive validity of constant irrelevant cues have no effect on solution rate of discrimination learning problems. The theories that do not include explicit attentional

Thanks are due to Jim Truscio and Jesse Osborne of the Singer Learning Center of Columbia, Maryland, for their active cooperation in the conduct of this research. Computer facilities were provided by the UMBC computer center. Reprint requests should be sent to M. A. Metzger, Department of Psychology, University of Maryland Baltimore County, Catonsville, MD 21228. responses predict otherwise: The rate of problem solution should vary inversely with the association of the constant irrelevant cues with reward.

\section{Empirical Background}

The association of relevant cues with reward contexts. Repetition of the positive cue in the reward context of a two-choice discrimination learning problem has been shown to facilitate problem solution by retarded children (Eimas \& Shepp, 1964; Shepp, 1964; Shepp, House, $\&$ Zeaman, 1967). The effect has also been shown in monkeys (Jarvik, 1956). A similar effect was found in cue selection in autoshaped keypecks by pigeons (Fisher \& Catania, 1975). The repetition has been brought about in several ways: by lining the reward well of a modified Wisconsin General Test Apparatus (WGTA) with a replica of the positive stimulus, by repeating a particular relevant cue of the positive stimulus in the reward [as in using a red candy reward for a red(+)-green(-) discrimination], or by using the reward itself as a discriminative stimulus [as in using Candy $A$ to reward a Candy $\mathrm{A}(+)$-Candy $\mathrm{B}(-)$ discrimination].

In all cases, when the reward context includes at least one positive cue from the discriminanda problem, solution is facilitated. When the reward context contains a negative cue from the discriminanda, problem solution is inhibited. The facilitation and inhibition of problem solution is consonant with the explanation by Shepp, House, and Zeaman (1967) that appeals to stimulus generalization from the reward context to $S+$ by means of shared conditioned elements: At the trial outcome, the approach response is elicited by the reward in the presence of the cues of $\mathbf{S}+$. By generalization, when $\mathbf{S}+$ is presented in the trial context, these cues again elicit approach.

The effects of repeating positive or negative cues in the reward context are consonant with both attentional and nonattentional theories. In the first theory, the differential association of positive and negative cues with reward amplifies (or moderates) attention to their common dimension. In the second theory, the increased association of the positive cue with reward reduces the associative strength accruing to other cues on a trial, whereas the in- 
creased association of the negative cue with reward reduces the associative strength accruing to the positive cue on a trial.

The association of irrelevant cues with reward contexts. A second kind of facilitation of problem solution through changes in the reward context has been demonstrated in two-choice discrimination learning both in trialsto-criterion learning (Estes, 1976) and in learning set formation (Metzger, in press). In both cases, subjects were children. Facilitation occurred when both the reward context and the nonreward context (the outcome of an error trial) contained constant irrelevant cues of the discriminanda.

Facilitation of learning set formation, due to the equal extratrial association of constant irrelevant cues with both reward and nonreward contexts, is not consonant with attentional theory interpretations of the processes involved in learning set formation. Variations in the associations of the constant irrelevant cues with reward should have no influence mediated by cue-relevance differences, because no such differences exist on any given trial. The effect on learning would have to be the result of influences on attention otherwise mediated, as in the encoding account of Estes (1976). Further support for the encoding interpretation was obtained when Metzger (in press) found that the experimental conditions of the learning set study affected the hypothesis structures of the subjects. The facilitated performance was characterized by an increase in both correct and incorrect object-related hypotheses. The facilitation is also consistent with the explanation of nonattentional theories; that is, more associative strength accrues from a reinforced trial on a cue in the presence of a poor predictor than in the presence of a good predictor.

In the Estes (1976) and Metzger (in press) experiments, the degree to which the facilitation can be attributed to effects mediated only by manipulation of the constant irrelevant cues is unclear since the experimental manipulation only incidentally affected this variable. The studies were directly concerned with changing object encodability.

It remains to be established to what extent variations in the association with reward of irrelevant cues, constant or variable, affect the speed of problem solution in two-choice visual discrimination learning tasks. Establishing these effects is relevant to theory, because a finding that constant irrelevant cues highly associated with reward interfere with problem solution would not be consistent with attentional theories. It would tend, rather, to give support to the nonattentional theories. Experiment 1 tests for this effect with constant irrelevant cues. Experiment 2 tests for the effect with variable irrelevant cues.

\section{EXPERIMENT 1}

\section{Method}

Each subject served in each of four experimental conditions, which were distinguished by the relevant dimension of the discrimination problem and by the relationship between the cue on the reward token and a constant irrelevant cue of the discriminanda. Neither the positive nor the negative cue from the discriminanda appeared in the reward context. The four conditions were determined by the two levels of relevant dimension (color or form) crossed with two levels of occurrence of a constant irrelevant cue from the discriminanda in the reward context (token same or token different). Four orders of problem presentation counterbalanced the order of the four conditions and the occurrence of intradimensional and extradimensional shifts (Zeaman \& House, 1963) in the second, third, and fourth problems. Each order was given to 4 subjects. Two color-relevant (form constant irrelevant) and two formrelevant (color constant irrelevant) problems were constructed. Rewards were tokens sharing the constant irrelevant cue of the problem (token same) or having a different cue on that dimension (token different). Table 1 illustrates the relationship between discriminanda and reward tokens in the two reward context conditions of Experiment 1. Assignment of a given problem to the same or different reward conditions was counterbalanced over orders. Designation of the positive and negative cue within each problem was counterbalanced over the assignment to reward conditions and orders. Right or left position for the positive stimulus on each trial was determined by a constrained random sequence.

Subjects. Sixteen preschool children served as subjects. Three children failed to solve the first problem within 100 trials and were replaced by other children. All children had previously served in a color-form pattern discrimination learning set experiment. The mean chronological age of the group was 53.1 months.

Materials and apparatus. A modified WGTA, as described in Metzger (in press), was used. Discriminanda were colored forms on white cards, approximately $9 \mathrm{~cm}$ square. Reward tokens were colored forms approximately $2.5 \mathrm{~cm}$ on the longest dimension.

Procedure. Children were brought individually to the experimental room and were presented with 20 trials per session on each problem until a criterion of 10 successive correct responses was attained. New problems were begun in new sessions. Noncorrection technique was used. Reward tokens could be exchanged for small toys.

\section{Results}

Table 2 displays the mean trial of last error (TLE) for each condition separately, according to the relevant dimension and ordinal position of the problem. The data show that repeating a constant irrelevant cue in the reward context interferes with problem solution (mean TLEs

Table 1

Examples of Discrimination Problems and Reward Contexts

\begin{tabular}{|c|c|c|c|c|}
\hline \multirow[b]{2}{*}{ Relevant Dimension } & \multicolumn{2}{|c|}{ Discriminanda } & \multicolumn{2}{|c|}{ Reward Token } \\
\hline & Positive & Negative & Same & Different \\
\hline $\begin{array}{l}\text { Experiment } 1 \\
\text { Color } \\
\text { Form }\end{array}$ & $\begin{array}{l}\text { Green Square } \\
\text { Yellow Triangle }\end{array}$ & $\begin{array}{l}\text { Red Square } \\
\text { Yellow Cross }\end{array}$ & $\begin{array}{l}\text { Blue Square } \\
\text { Yellow Diamond }\end{array}$ & $\begin{array}{l}\text { Blue Circle } \\
\text { Brown Diamond }\end{array}$ \\
\hline $\begin{array}{l}\text { Experiment } 2 \\
\text { Form }\end{array}$ & $\begin{array}{l}\text { Green Square } \\
\text { Red Square }\end{array}$ & $\begin{array}{l}\text { Red Circle } \\
\text { Green Circle }\end{array}$ & Red Triangle & Blue Triangle \\
\hline
\end{tabular}


Table 2

Mean Trial of Last Error for Conditions of Experiment 1

\begin{tabular}{ccrr}
\hline \multirow{2}{*}{$\begin{array}{c}\text { Serial } \\
\text { Position }\end{array}$} & $\begin{array}{c}\text { Relevant } \\
\text { Dimension }\end{array}$ & Same & Different \\
\hline 1 & Form & 13.0 & 15.5 \\
1 & Color & 27.8 & 13.0 \\
2 & Form & 17.3 & .5 \\
2 & Color & 15.8 & 4.5 \\
3 & Form & 3.8 & .8 \\
3 & Color & 3.5 & 2.2 \\
4 & Form & 1.8 & .5 \\
4 & Color & 3.3 & .3 \\
Mean & & 10.8 & 4.7 \\
\hline
\end{tabular}

of 10.8 and 4.7 trials for the same and different reward context conditions, respectively).

For the analysis of variance, the dependent variable $\log$ (TLE+1) was used, in order to make the distributions more nearly normal. In addition, because the means and standards deviations of the problems changed with serial position, each score was transformed to deviation units from the mean log score for all problems in its serial position. In this way, the effects of serial position were removed before the analysis was done. The scores were then combined over all serial positions for analysis. An order (4) $\times$ dimension (color relevant or form relevant) $\times$ reward context (same or different) ANOVA, with dimension and reward context as within-subjects factors, revealed a significant main effect of reward context $[F(1,12)=4.99, p<.05]$. No other effects or interactions were significant.

\section{Discussion}

Experiment 1 confirms that repetition of the constant irrelevant cue in the reward context inhibits solution of the discrimination learning problem. Irrelevant cues of a problem may also be variable; that is, each trial may contain two values of the irrelevant dimension. This second case was the topic of Experiment 2.

\section{EXPERIMENT 2}

\section{Method}

Two form-relevant, color-variable and -irrelevant problems were constructed. All reward tokens were disks having either the same color as one of the variable irrelevant cues of the problem or a color different from both of the variable irrelevant cues. Each child had two problems, one with an irrelevant color cue of the problem repeated in the reward context (same), and one with a different color cue in the reward context (different). The order of these conditions, the assignment of particular problems to each of the conditions, and the designation of the positive stimulus for each problem were counterbalanced over subjects. Noncorrection technique was used. Position of the positive stimulus on each trial was determined by a constrained random sequence.

Subjects. Eight children were chosen at random from the subjects of Experiment 1. One subject, who failed to solve the first problem, and 1 , who made no errors on either problem, were replaced. The mean chronological age of the group was 54.6 months.

Materials, apparatus, and procedure. Materials, apparatus, and procedure were as in Experiment 1.

\section{Results}

The mean TLE was 18.5 for the same condition and 3.5 for the different condition. An order (same-to-different or different-to-same) $\times$ reward context (same or differ- ent). ANOVA, with reward context a within-subjects factor, was performed on $\log$ (TLE +1$)$ scores. The difference was significant $[F(1,6)=7.59, p<.05]$. No other main effect or interaction was significant. In the same condition, children showed a preference for the repeated irrelevant cue.

\section{Discussion}

Experiments 1 and 2 and Metzger's (in press) learning set experiment show that when either a constant irrelevant cue or a variable irrelevant cue of a two-choice visual discrimination learning problem is otherwise associated with the reward context, the solution rate for the problem is adversely affected. The results for constant-irrelevant cues are not compatible with attentional theories of discrimination learning. The results for variable irrelevant cues are consistent with attentional theory only if the theory contains some feedback mechanism through which cue-significance difference may moderate effective attention to the dimension.

\section{REFERENCES}

Eimas, P. D., \& SHEPP, B. E. (1964). Retardate discrimination learning following differential conditioning of the choice-point stimuli. Child Development, 35, 685-693.

ESTES, K. W. (1976). An information processing analysis of reinforcement in children's discrimination learning. Child Development, 47, 639-647.

Fisher, M. A., \& CATANiA, A. C. (1975). Autoshaping: Relation of feeder color to choice of key color. Bulletin of the Psychonomic Society, 9, 439-442.

Fisher, M. A., \& Zeaman, D. (1973). An attention-retention theory of retardate discrimination learning. In N. Ellis (Ed.), International review of research in mental retardation, (Vol. 6). New York: Academic Press.

JARVIK, M. E. (1956). Simple color discrimination in chimpanzees: Effect of varying contiguity between cue and incentive. Journal of Comparative \& Physiological Psychology, 49, 492-495.

LOVEJoY, E. (1975). Attention in Discrimination Learning. San Francisco: Holden-Day.

MACKINTOSH, N. J. (1975). A theory of attention: Variations in the associability of stimuli with reinforcement. Psychological Review, 82, 276-298.

METZGer, M. A. (in press). Reward context: Influence on hypotheses during learning set formation in preschool children. Psychological Reports.

Miller, G. A. (1983). Cognition and comparative psychology. The Behavioral \& Brain Sciences, 6, 152-153.

PremaCK, D. (1983). The codes of man and beasts. The Behavioral \& Brain Sciences, 6, 125-137.

Rescorla, R. A., \& WAGner, A. R. (1972). A theory of Pavlovian conditioning: Variations in the effectiveness of reinforcement and nonreinforcement. In A. H. Black \& W. F. Prokasy (Eds.). Classical conditioning II: Current research and theory. New York: AppletonCentury-Crofts.

SHEPP, B. E. (1964). Some cue properties of rewards in simultaneous object discriminations of retardates. Child Development, 35, 587-592.

Shepp, B. E., House, B., \& Zeaman, D. (1967). Continuity and imbeddedness factors in the discriminative learning of retardates. Journal of Experimental Child Psychology, 5, 604-611.

Sutherland, N. S., \& Mackintosh, N. J. (1971). Mechanisms of animal discrimination learning. New York: Academic Press.

WAGNER, A. R. (1969). Stimulus selection and a "modified continuity theory." In G. H. Bower (Ed.), The psychology of learning and motivation (3rd ed.). New York: Academic Press.

Zeaman, D., \& House, B. J. (1963). The role of attention in retardate discrimination learning. In N. R. Ellis (Ed.), Handbook of mental deficiency. New York: McGraw-Hill.

(Manuscript received for publication September 30, 1985.) 